\title{
Research on Safety Measures of Distributed PV generation System
}

\author{
Nan Liu \\ State Grid Dalian Electric Power Supply Company \\ Dalian, China \\ dlliunan@163.com
}

Yan Chen

Dalian Electric Power Survey \& Design Institute CO. Ltd

Dalian, China

15842495990@163.com

\author{
Yi Du \\ State Grid Dalian Electric Power Supply Company \\ Dalian, China \\ duyi@163.com \\ Quanlei Luo \\ State Grid Dalian Electric Power Supply Company \\ Dalian, China \\ lq1@163.com
}

\begin{abstract}
Distributed PV generation system is an important way currently for distributed power construction. Affected by device characteristics and installation features, it suffers a higher probability of failure, so its impact on the public grid is more than ordinary electrical equipment. In order to prevent the failure of the distributed PV system, we analysis the various factors that affect the safe operation of distributed PV generation system. According to engineering practices, measures of lightning protection, relay protection and automatic device, maintenance and protection, preventing damages caused by small animals, spot investigation, safety signs, spot check and acceptance, operation management are put forward and discussed in detail. At the same time, diagram of lightning protection measures of solar power system and diagram of safety measures of solar power system are drawn. Based on the analysis of engineering practice, this paper puts forward all kinds of safety measures through the work of distributed PV station access to grid should take, which has good application value.
\end{abstract}

Keywords-component; Distributed PV generation system; safety measures; research; engineering practice; application value

\section{INTRODUCTION}

Distributed PV generation system connected to the grid consists of the body of PV power station and system equipmentconnected to the grid. Because of its flexible installation, easy construction, unlimited investment and quick returns, it is an important way currently for distributed power construction. Distributed PV generation system,affected by device characteristics and installation features, suffers a higher probability of failure, so its impact on the public grid is more than ordinary electrical equipment. Therefore, in the work of the PVgeneration system design, installation, operation, maintenance and so on, much importance should be attached to its security and appropriate measures should be taken to prevent it.

\section{SAFETY THREATS OF DISTRIBUTED PV GENERATION SYSTEM}

Factors affecting normal use of distributed PV generation system are mainly classified into three types.

(1) Natural factors: It mainly refers that the overvoltage produced by lightning affects the normal operation of equipment; many PV power stations are installed in high positions with a large area, so their lightning strike probability is higher than that of general equipment. Lightening makes damage to PV generation system mainly through direct lightning, lightning induction and lightning wave invasion. Direct lightning is strong discharge between the charged cumulus clouds and PV power station ground equipment as well as lines, which has the strongest damage effect; lightning induction is electrostatic induction and electromagnetic induction produced in the vicinity of conductors when lightning discharges, which is possible to make metal parts spark and subsequently damage equipment; lightning wave invasion is that the pulse electrical surge generated by overhead lines suffering lightning strikes invades inner PV generation system, which makes damage to equipment [1]. In addition to lightning, the small animals' invasion in rural areas causing a short circuit and equipment damage also must be paid attention to.

(2) Equipment failure: When inverters, grid-connected circuit breakers and other key equipment in the PV generation system fail to work, it will seriously affect the normal operation of PV power stations, and is likely to cause their outage. When public grid lines connecting PV power stations are impacted by overvoltage, they will be transmitted to the body of PV power stations, thus damaging the equipment.

(3) Human factors: Distributed PV power station under installation normally does not have a closed enclosure, so incorrect behavior of non-workers may cause outages for equipment failure and occurrence of safety accidents; incorrect operation of staff in the process of installation, operation and maintenance of PV generation system equipment can damage the equipment and cause safety accidents. 


\section{SAFETY MEASURES}

Targeted at safety threats faced by distributed PV generation system, corresponding measures should be taken to prevent or reduce the adverse impact of the accidents. There are two main safety measures: technical measures and management measures.

\section{A. Technical measures}

Technical measures are generally adopted in the process of program formulation, design and site construction of distributed PV generation system, mainly including lightning prevention, islanding protection, voltage losing blocking as well as overhaul ground protection and other measures.

\section{1) Lightning protection measures}

Distributed PV generation system is able to prevent lightening mainly through installing external lightning rod and the Faraday cage, as well as internal equipotential bonding system, shielding system, surge protectors and other equipment ${ }^{[1]}$. Taking into account of the on-site installation convenience and subsequent maintenance needs, the Faraday cage is rarely used, but the combination of lightning rod - the equipotential bonding system - surge protector(arrester) or the equipotential bonding system surge protector (arrester) is more common, as shown below:

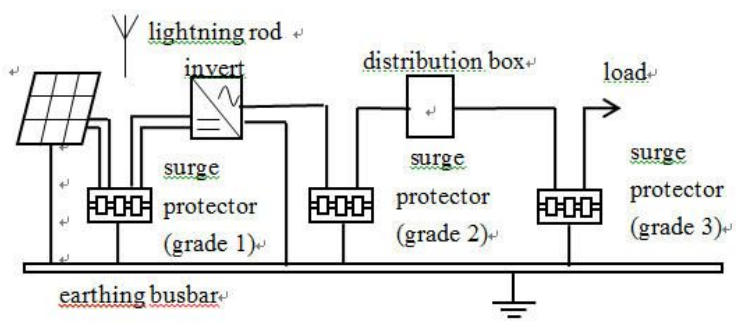

Figure1. Diagram of lightning protection measures of solar power system

Lightning rod is installed on top of PV module, and is connected with earthingbusbar in the lower part, so the lightening can be brought to the ground to protect PV module from the hazards of direct lightning strikes. The scope of the lightning rod generally employs "Rolling ball method", which is calculated as follows:

In the formula: Protection field radius centered by lightning rod is the height of lightning rod, the height of PV module, and the radius of rolling ball. The building of type 1 is 30 meters; the building of type 2 is 45 meters, and the building of type 3 is 60 meters ${ }^{[2]}$. Given that solar panels are mainly installed on the roof of general industrial and civil buildings or on the ground, the height is usually set at 60 meters.

Surge protector, designated for low-voltage power supply system, is mainly used for transient overvoltage protection. In general, the way of grading installation is employed. Starting from the entrance of the power supply system, the surge energy is absorbed layer by layer ${ }^{[3]}$. As Figure 1 shows, distributed PV generation system should be equipped with surge protectors between solar panels and inverters, between the inverter and the distribution box, and between the distribution box and the load respectively, in which parameters requirements of nominal discharge current (In), the maximum discharge current (Imax), and response time $(\mathrm{t})$ are as follows:

TABLE I. Parameter table of distributed PV generation system surge protectors

\begin{tabular}{|l|c|c|c|}
\hline $\begin{array}{l}\text { Protection } \\
\text { grade }\end{array}$ & $\begin{array}{l}\text { Nominal } \\
\text { discharge } \\
\text { current } \\
(\boldsymbol{k} \text { A) }\end{array}$ & $\begin{array}{l}\text { Maximum } \\
\text { discharge } \\
\text { current } \\
(\boldsymbol{k} \text { A) }\end{array}$ & $\begin{array}{l}\text { Response } \\
\text { time (ns) }\end{array}$ \\
\hline Grade 1 & 80 & 160 & 100 \\
\hline Grade 2 & 40 & 80 & 50 \\
\hline Grade 3 & 20 & 40 & 25 \\
\hline
\end{tabular}

Distributed PV system must take good grounding measures. The grounding way of distributed power source should be consistent with that of grid side, and should meet the requirements of personnel and equipment safety as well as protection collaboration ${ }^{[4]}$.

Grounding of distributed PV power station can be set independently, but it is recommended that it should be connected to the grounding of buildings. When it is in independent grounding, the grounding resistance should meet $\mathrm{R} \leq 4 \Omega$, while when it is connected to industrial plants, the grounding resistance should meet $\mathrm{R} \leq 1 \Omega$ to effectively shield lightning wave shock and prevent electrostatic interference.

2) Measures of relay protection and automatic device

Inverters of PV power stations accessed to the public grid must have the capacity of rapidly monitoring silos and immediately disconnecting with grid after the monition in case when public grid loses voltage, grid-connected PV power station still supply powers out, thus leading to personnel injury and circuit breaker malfunction accidents. Anti-islanding protection of inverters should be compatible with the grid side line protection, and its action time should be verified and matched to the public grid line protection to avoid non-simultaneous switching ${ }^{[5]}$.

The grid-connected PV power station shall set circuit breakers of grid-connected point behind the alternating current side of the inverter. The circuit breaker of gridconnected point shall adopt the low voltage grid dedicated circuit breakers, which are easy to operate, with obvious open and break instructions, and with the function of open and break fault current. The dedicated circuit breaker protection shall have the function of no-voltage tripping and checking voltage switching on. The constant value of no-voltage tripping shall adjust to $20 \% \mathrm{Un}$ every 10 seconds, and the constant value of checking voltage shall adjust to $85 \% \mathrm{Un}$. From the perspective of economic technology, small PV power stations within $20 \mathrm{~kW}$ can use small circuit breakers with no-voltage releases as girdconnected circuit breakers; big PV power stations can use frame-type universal circuit breakers or molded case circuit breakers with the function of no-voltage blocking as gird-connected point circuit breakers.

High capacity is accessed to the PV power station of the public grid through voltage level of $10 \mathrm{kV}$ or more than $10 \mathrm{kV}$, and it must take the set of the station, the relay protection of $66(35) \mathrm{kV}$ converting station and the automatic device into consideration. When accessed to the PV power station of the $66(35) \mathrm{kV}$ converting station through dedicated circuit, adopting the optical fiber 
longitudinal differential protection device can meet the protection needs. When accessed to the grid with $\mathrm{T}$ accessing mode, far-tripping device can be set. Whenthe public grid breaks off power supply because of faults, maintenance and other reasons, the circuit breaker at the exit of the PV power station trips off at the same time, to avoid occurring the PV power station island operation.

Large distributed PV power stations shall be equipped with unified synchronous clock equipment or using the network for time setting with the grid to correct every measurement and control unit equipment $\operatorname{clock}^{[6]}$. Computer monitoring and control system equipment at PV power stations shall adopt alternating current uninterrupted power supply (UPS) system to supply power. The continuous power supply time of the alternating current uninterrupted. power supply system is no less than $1 \mathrm{~h}^{[7]}$.

3) Measures of maintenance and protection

As for the power points installed at the public areas, there must be measures of ground connection, insulation protection or adding locks, hanging signs at the breaking points while maintenance to ensure the safety of maintainers and equipment. If the connection point of the PV power station and the public grid is overhead insulation-covered conductor, then it is necessary to think about reserving grounding device at the circuit for the convenience of checking the normal installment of ground wires under power cut or other conditions.

4) Measures of preventing damages caused by small animals

Some PV power stations at rural areas are installed on the ground. Small animals may invade power supply facilities, and therefore lead to short circuit or open circuit, which affect the normal operation of equipment. Therefore, certain sealing and keeping out measures shall be taken. Fences shall be set outside the PV power station, and the power supply cables shall be protected by sealing pipes; as for overhead pole bracing wires, protective facilities for preventing small animals climbing shall be installed.

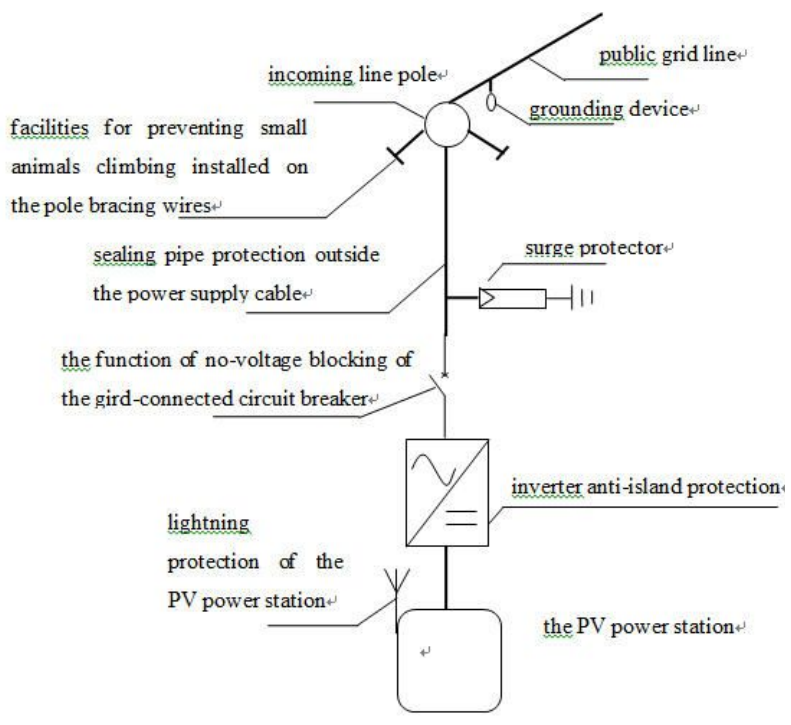

Figure2. Diagram of safety measures of solar power system

\section{B. Management measures}

The safety management at the PV power station shall be started from spot investigation, and adopt related safety management measures during site operation, check and acceptance, and operation management.

1) Spot investigation

Spot investigation refers to the important link of mastering the construction plan and environment features of the PV power station, and clarifying the safety measures. Through investigations of users' different PV power station construction types under different environments, suggestions of protecting the safety of generating system can be put forward to users, and at the same time, corresponding safety measures of the access system plan and design can be well prepared.

2) Safety signs

As for the distributed PV power station that connects grids with $380 \mathrm{~V}$ voltage level, there should be marked signs on the special low-voltage switchgear that connects the power and grid. Signs shall mark with "warning", "double power" or other indicative words or symbols. The shape, color, size and height of signs shall follow the GB 2894 Safety Signs and Guideline for the Use.

The distributed PV power station that connects grids with $10 \mathrm{kV}(6 \mathrm{kV}) \sim 35 \mathrm{kV}$ voltage level shall make "Danger High Voltage" and other indicative words or symbols near electrical equipment and circuits according to the GB 2894 Safety Signs and Guideline for the Use ${ }^{[8]}$.

3) Spot check and acceptance

Main task of spot check and acceptance is to check whether the whole PV power generating system meets the requirements of regulations and norms, and whether it operates safely and reliably. Therefore, there is a need to check the qualifications of the construction unit and the administrative unit of PV power station to make sure they are in accordance with the requirements of the national policy. Meanwhile, check technical parameters, type approval report, quality report, certificate of qualification and other documents of the PV power station and access system device provided by users. Among them, PV panels, inverters and other devices shall get certification report of testing agency with qualification authorized by the state. Key devices shall take simulation motion tests on site, such as inverter preventing island protection operation test, no-voltage blocking test of the gird-connected circuit breaker. It can pass the check and acceptance if there is no problem.

4) Operation management

Before grid-connecting of distributed PV power stations, the grid administrative unit shall clarify the safety responsibilities and obligations of both sides with the user by an agreement. Meanwhile, according to the operational condition of the distributed PV power station, real-time update the system wiring diagram, and give obvious operation instructions of the grid-connected devices installment. When maintaining the grid, the administrative unit shall clearly inform the users of the distributed PV power station, and make well measures of isolation, grounding, locking or hanging signs by cooperating with users.

Grid dispatching center shall sign a dispatching agreement with users of the PV power station ${ }^{[9]}$. As for the distributed PV power station that accesses to the high 
voltage distribution network, master conditions of open and break devices at grid-connected points, and according to the grid construction, maintenance and operation needs, carry out the order of start and stop. As for the distributed PV power station that accesses to the low voltage distribution network, master its operation condition, and clarify safety measures while gridoperating ${ }^{[10]}$.

\section{Footnotes}

The popularization of distributed PV power stations brings many unstable factors of safety to traditional public grid. It is necessary to follow the requirements of regulations and norms, and according to spot conditions, to enforce management through technique to ensure the safe and stable operation of the PV generation system and the public grid.

\section{REFERENCES}

[1] GaoJinhui, Ma Gaofeng, Wang Hongni. Lighting protection design of the PV generation system[J]. Journal of Henan Normal University, Vol.41, No.3, 2013, pp.42-43.

[2] ShuYinbiao, Zhang Liying, Wang Xiangqin, etc. Distributed PV Access Systems Typical Design, 2012, pp.37-38

[3] GB50057-2010 Design Code for Protection of Structures AgainstLightning, China Machinery Industry Federation, pp.9-10.

[4] WangShiyuan, Chen jingxin, Zhenyunyun. Lighting Protection Structure Design of The PV Generation System. Solar Power, No.2, 2011, pp.41-44.

[5] Q/GDW480-2010 TechnicalRule for Distributed Power Sources Connected to Power Grid. State Grid Corporation of China, pp.7-8.

[6] Typical Design of Distributed PV Power Access System, China Electric Power Press, pp.62

[7] GB 50797-2012 Design Code for PV Power Station, China Planning Press, pp. 36.

[8] Typical Design of Distributed PV Power Access System, China Electric Power Press, pp. 28

[9] Lightning Protection Design for Photovoltaic Integrated Building, Solar Power, No.2, 2011, pp.42-45.

[10] Working Safety Regulation for Power Industry of State Grid Corporation of China (Distribution) (trial implementation), China Electric Power Press, pp.63-65. 